\title{
Effects of Abscisic Acid on Photosynthetic Characteristics of Radish under Aluminum Stress
}

\author{
Xuena $\mathrm{Yu}^{1, \mathrm{a}}$, Jun $\operatorname{Tan}^{2, \mathrm{~b}}$ and Yi Tang ${ }^{1, \mathrm{c} *}$ \\ ${ }^{1}$ Institute of Pomology and Olericulture, Sichuan Agricultural University, Chengdu, Sichuan, China \\ ${ }^{2}$ College of Horticulture, Sichuan Agricultural University, Chengdu, Sichuan, China \\ ayxn4842@sina.cn, b987831264@qq.com, ctangyisunguochao@sina.com \\ ${ }^{*}$ Corresponding author
}

Keywords: Abscisic acid; Radish; Photosynthetic characteristics

Abstract. A pot experiment was conducted to study the effects of exogenous abscisic acid (ABA) on photosynthetic characteristics of radish under aluminum (Al) stress. Five treatments were used in the experiment: seeds were soaked with $0(\mathrm{CK}), 1,5,10$ and $20 \mu \mathrm{mol} \cdot \mathrm{L}^{-1}$ concentrations of abscisic acid solution. The results showed that abscisic acid enhanced net photosynthetic rate (Pn) of radish significantly. With the increasing of abscisic acid concentration, Pn of radish was enhanced significantly, and when the concentration was $10 \mu \mathrm{mol} \cdot \mathrm{L}-1, \mathrm{Pn}$ of radish reached the highest. The result of transpiration rate (Tr), light use efficiency (LUE) and water use efficiency (WUE) were the same as Pn. However when concentration of abscisic acid is too high, Gs of radish decreased. Soaking different concentrations of abscisic acid on radish under aluminum stress has not significant effect on $\mathrm{CO}_{2}$ concentration of intercellular (Ci). Therefore, abscisic acid could use to enhance the photosynthetic ability of radish, which would help to improve the adaptability of radish, and the best concentration of melatonin was $10 \mu \mathrm{mol} \cdot \mathrm{L}-1$.

\section{Introduction}

In recent years, with the rapid development of industry, problems of environmental pollution have become increasingly serious. Acidification of atmosphere, excessive use of pesticides and fertilizers causes soil acidification intensifies, and soluble aluminum content in soil increased significantly. Studies have shown that low concentrations of aluminum can promote the growth of plants, but the concentration of aluminum increased to a certain extent, it will be toxic to plants [1]. It was found that aluminum stress is the main limiting factor for crops in acid soils, can cause crop losses of $40 \%$ [2]. So the study of how to ease aluminum stress is very important.

Abscisic acid is a plant endogenous hormones related with plant growth and development[3]. It has effect on inhibiting seed germination, inhibiting of cell elongation and promoting aging [4]. As a stress signal, abscisic acid plays an important role in regulating balance of substances in the plant and inducing resistance of stress [5-7].

Radish (Raphanus sativus L.) is rich in nutrients, has good food value and medicinal value, are widely cultivated throughout China[8].

In this study, we used different concentrations of abscisic acid to soak radish seeds for the purpose of screening the influence of abscisic acid on photosynthetic characteristics of radish under aluminum stress.

\section{Materials and Methods}

Materials. The experiments were conducted at Sichuan Agricultural University $\left(30^{\circ} 42^{\prime} \mathrm{N}, 103^{\circ} 51^{\prime}\right.$ E), Wenjiang, China. The seeds of radish named red skin radish were harvested in 2014 and purchased from Chengdu, China. All chemicals used in experiments were of analytical grade.

Experimental Design. Selected the same size and full of radish seeds, placed in five test tubes, soaked with $0(\mathrm{CK}), 1,5,10,20 \mu \mathrm{mol} \cdot \mathrm{L}^{-1}$ concentrations of abscisic acid solution for $24 \mathrm{~h}$, added 50 $\mathrm{mL}$ abscisic acid solution in every test tubes, respectively. There were 20 seeds in each test tube. 
After germination, seeds were planted in nutrition pot filled with vermiculite and perlite, the pot was ten centimeters in diameter and height. Each treatment consisted of 10 pots with one plant per pot.

When the cotyledons growed, seedlings were irrigated with $20 \mathrm{ml}$ Hoagland nutrient solution containing $50 \mu \mathrm{mol} \cdot \mathrm{L}^{-1}$ concentrations of aluminum chloride every three day, watering according to weather conditions, until the experiment finishing. Positions of the pots were randomly changed daily to minimize positional effects. 45 days after treatment, the photosynthesis of each plant was determined by using LI-6400 portable photosynthesis meter (LI-COR Inc., USA). The photosynthetic parameters of the photosynthesis meter were manual control $\mathrm{CO}_{2}$ concentration $400 \mu \mathrm{mol} \cdot \mathrm{CO}_{2} \mathrm{~mol}^{-1}$, temperature $25^{\circ} \mathrm{C}$, light intensity $1200 \mu \mathrm{mol} \mathrm{m}{ }^{-2} \cdot \mathrm{s}^{-1}$. The determination of photosynthetic parameters were net photosynthetic rate $(\mathrm{Pn})$, transpiration rate $(\mathrm{Tr})$, stomatal conductance $(\mathrm{Gs})$ and $\mathrm{CO}_{2}$ concentration of intercellular $(\mathrm{Ci})$, and each treatment was repeated three times. Water use efficiency $(\mathrm{WUE})=$ net photosynthetic rate $(\mathrm{Pn}) /$ transpiration rate $(\mathrm{Tr})$, Light use efficiency $(\mathrm{LUE})=$ net photosynthetic rate $(\mathrm{Pn}) /$ light intensity.

Statistic analyses. Statistical analyses were performed using SPSS 13.0 statistical software (IBM, Chicago, IL, USA). Data were analyzed by one-way ANOVA with least significant difference (LSD) at a $5 \%$ confidence level.

\section{Results and Discussion}

Net Photosynthetic Rate (Pn). Compared with CK, abscisic acid enhanced Pn of radish under Al stress significantly, and the Pn of radish was increased with the increasing of abscisic acid concentration (Fig. 1). When the concentration of abscisic acid were 1,5 and $20 \mu \mathrm{mol} \cdot \mathrm{L}^{-1}$, these treatments enhanced Pn of radish by $17.73 \%(p<0.05), 31.77 \%(p<0.05)$ and $6.86 \%(p>0.05)$ respectively, compared with $\mathrm{CK}$. When the concentration of abscisic acid was $10 \mu \mathrm{mol} \cdot \mathrm{L}^{-1}$, Pn of radish reached the highest, and increased by $68.98 \%(p<0.05)$. In this study, it was illustrated that abscisic acid can alleviate the Al stress and improve photosynthetic capacity of radish seedlings.

Transpiration Rate (Tr). Abscisic acid increased the $\operatorname{Tr}$ of radish (Fig. 2). The trend of $\operatorname{Tr}$ was consistent with Pn. Compared with CK, When the concentration of abscisic acid were 1, 5 and 20 $\mu \mathrm{mol} \cdot \mathrm{L}^{-1}$, these treatments enhanced $\mathrm{Tr}$ of radish by $15.31 \%(p<0.05), 26.91 \%(p<0.05)$ and $1.31 \%$ $(p>0.05)$ respectively, compared with CK. When the concentration of abscisic acid was $10 \mu \mathrm{mol} \cdot \mathrm{L}^{-1}$, Tr of radish reached the highest, and increased by $56.24 \%(p<0.05)$. It was showed that abscisic acid can alleviate the Al stress of radish seedlings.

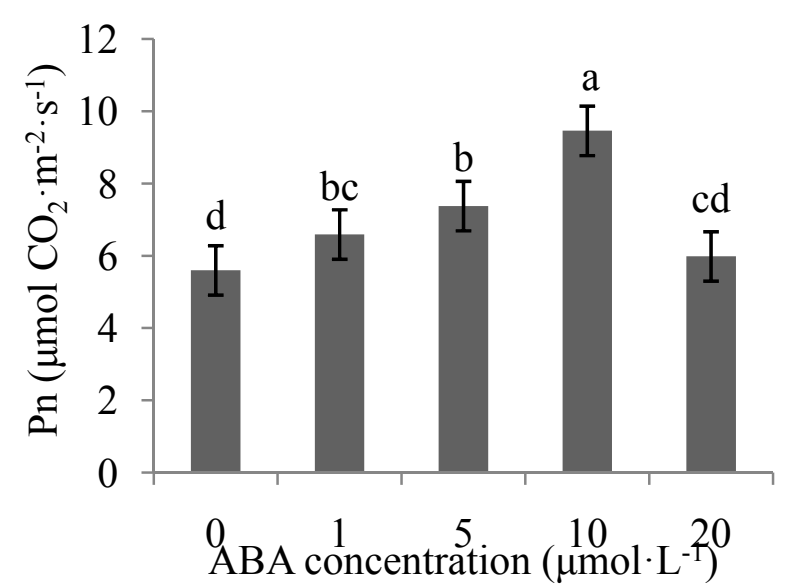

Fig. 1 Pn of ABA soaked radish

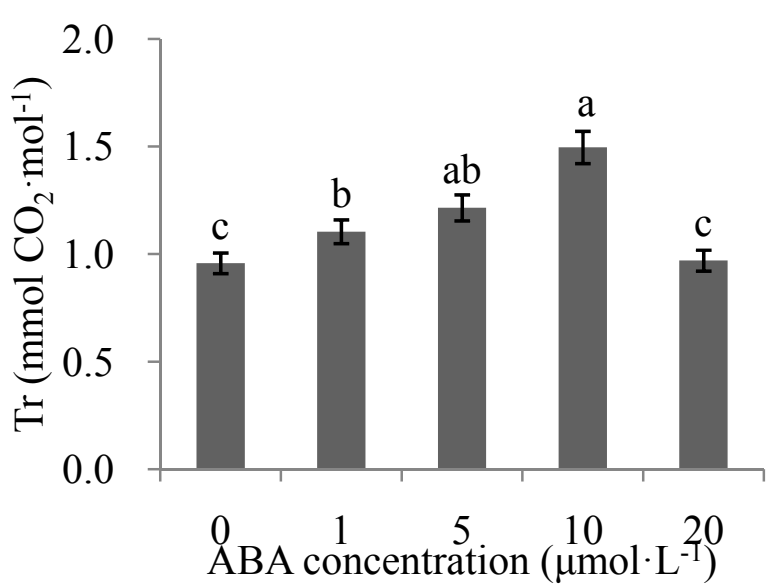

Fig. 2 Tr of ABA soaked radish 
Water Use Efficiency (WUE). Compared with CK, When the concentration of abscisic acid were 1,5 and $20 \mu \mathrm{mol} \cdot \mathrm{L}^{-1}$, these treatments enhanced WUE of radish by $2.11 \%(p>0.05), 3.83 \%(p>$ $0.05)$ and $5.48 \%(p>0.05)$ respectively. When the concentration of abscisic acid was $10 \mu \mathrm{mol} \cdot \mathrm{L}^{-1}$, WUE of radish reached the highest, and increased by $8.15 \%(p<0.05)$. It was showed that suitable concentration of abscisic acid can alleviate the Al stress.

Light Use Efficiency (LUE). Abscisic acid increased the LUE of radish with the increasing of abscisic acid concentration under Al stress (Fig. 4). When the concentration of abscisic acid were 1, 5 and $20 \mu \mathrm{mol} \cdot \mathrm{L}^{-1}$, these treatments enhanced LUE of radish by $17.73 \%(p<0.05), 31.77 \%(p<0.05)$ and $6.86 \%(p>0.05)$ respectively, compared with CK. When the concentration of abscisic acid was $10 \mu \mathrm{mol} \cdot \mathrm{L}^{-1}$, LUE of radish reached the highest, and increased by $68.98 \%(p<0.05)$. It was showed that abscisic acid can alleviate the $\mathrm{Al}$ stress of radish seedlings.

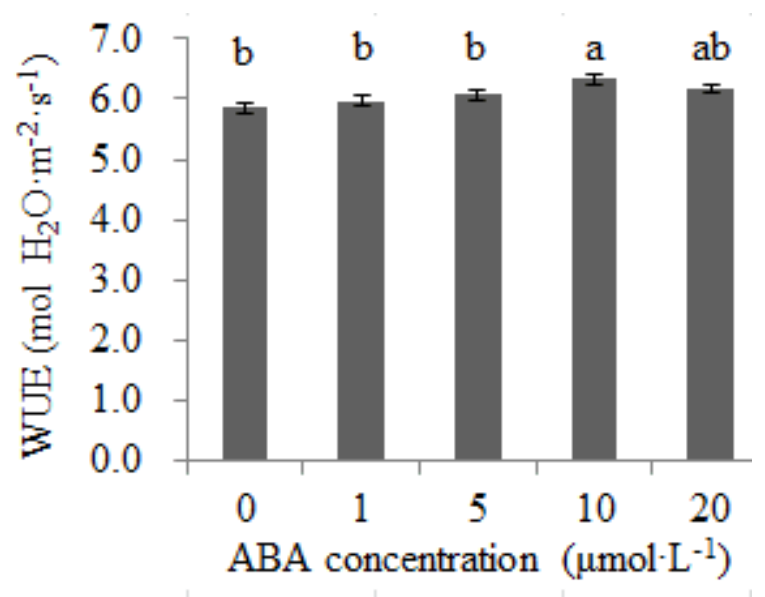

Fig. 3 WUE of ABA soaked radish

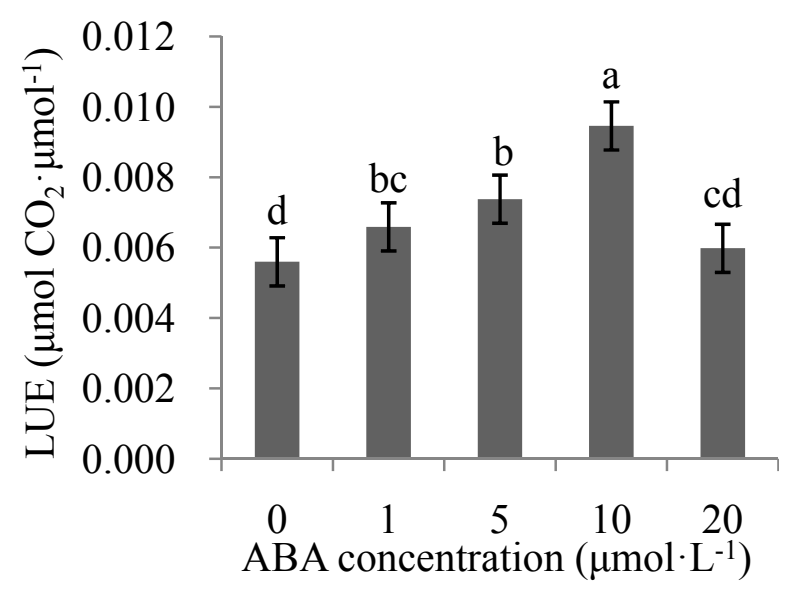

Fig. 4 LUE of ABA soaked radish

Stomatal Conductance (Gs). After soaked with abscisic acid, Gs of radish increased (Fig. 5). Compared with CK, When the concentration of abscisic acid were 1,5 and $10 \mu \mathrm{mol} \cdot \mathrm{L}^{-1}$, these treatments enhanced Gs of radish by $28.41 \%(p>0.05), 80.12 \%(p<0.05)$ and $108.37 \%(p<0.05)$ respectively. When concentration of abscisic acid is too high $\left(20 \mu \mathrm{mol} \cdot \mathrm{L}^{-1}\right)$, Gs of radish decreased by $17.23 \%(p>0.05)$ compared with CK.

$\mathrm{CO}_{2}$ Concentration of Intercellular (Ci). Difference between soaked with different concentrations of abscisic acid were not significant. It is illustrated that the effect on $\mathrm{Ci}$ of abscisic acid was not obvious.

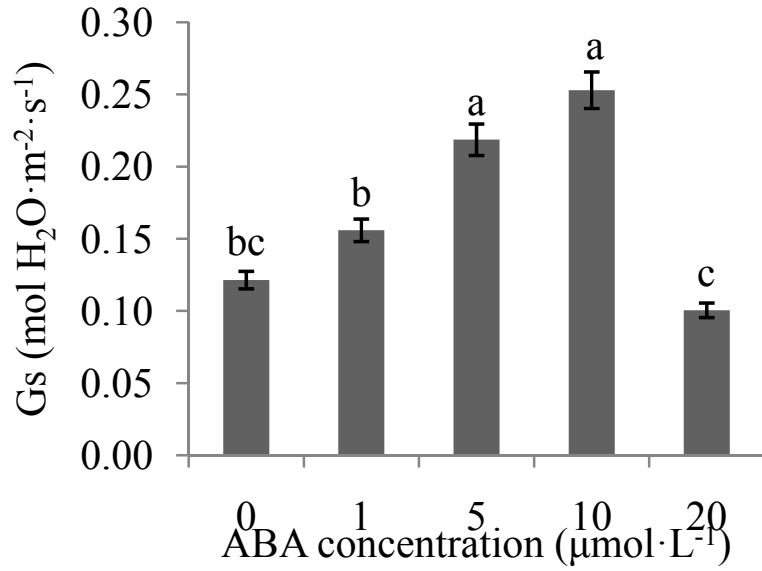

Fig. 5 Gs of ABA soaked radish

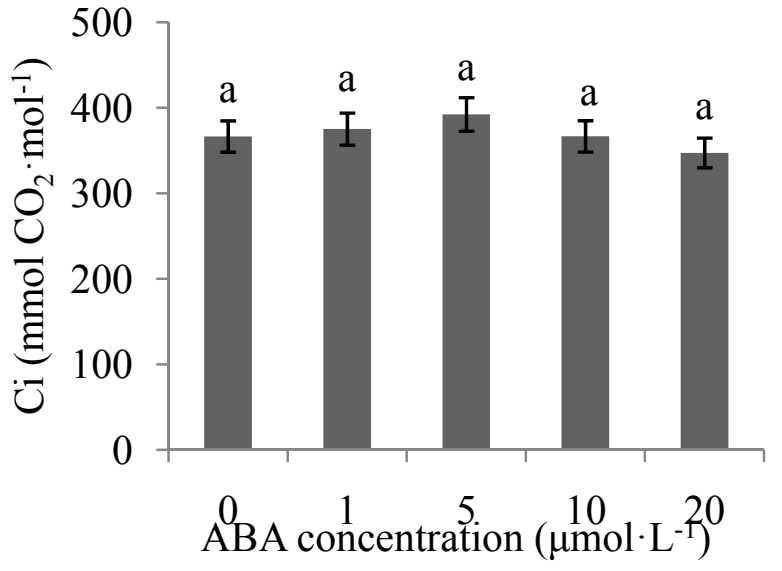

Fig. $6 \mathrm{Ci}$ of ABA soaked radish 


\section{Conclusions}

Abscisic acid can alleviate the Al stress on photosynthetic organ damage and improve photosynthetic capacity of radish seedlings. With the increasing of abscisic acid concentration, Pn of radish was enhanced significantly, and when the concentration was $10 \mu \mathrm{mol} \cdot \mathrm{L}^{-1}$, Pn of radish reached the highest. The result of Tr, LUE and WUE were the same as Pn. However when concentration of abscisic acid is too high, Gs of radish decreased. Soaking different concentrations of abscisic acid on radish under aluminum stress has not significant effect on $\mathrm{Ci}$. Therefore, abscisic acid could use to enhance the photosynthetic ability of radish, which would help to improve the adaptability of radish.

\section{Acknowledgements}

This work was financially supported by the Sichuan Agricultural University "Shuang-Zhi Plan" Foundation.

\section{References}

[1] X.L. Zheng and H.L. Ye: Chinese Journal of Applied Ecology Vol. 21 (2010), p.1998-2003 (In Chinese).

[2] J.F. Ma and P.R. Ryan: Functional Plant Biology Vol. 37 (2010), p.3-6 .

[3] J. Leung and J. Giraudal: Annual Review of Plant Physiology and Plant Molecular Biology Vol. 49(1998), p.199-222.

[4] M. J. Holdsworth and S. Finch: Trends in Plant Science Vol. 13 (2008), p.7-13

[5] M. Perras and F. Sarhan: Plant Physiology Vol. 89 (1989), p.577-585

[6] Y. Fujita and K. Shinozaki: Journal of Plant Research Vol. 124(2011), p.509-525

[7] A.S. Raghavendra and V.K. Gonugunta: Trends in Plant Science Vol. 15 (2010), p.395-401

[8] J.S. Li, R. Yang and X.L. Sui: Acta Agriculturae Boreali-Sinica Vol. 23(2008), p.77-80 (In Chinese). 